\title{
Long-term change in rainfall distribution in Northeast Thailand: will cropping systems be able to adapt?
}

\author{
Guillaume Lacombe ${ }^{1, *}$, Anan Polthanee ${ }^{2}$ and Guy Trébuil ${ }^{3}$ \\ ${ }^{1}$ International Water Management Institute (IWMI), Southeast Asia Regional Office, PO Box 4199, Vientiane, Lao Democratic People's \\ Republic \\ 2 Department of Plant Science and Agricultural Resources, Faculty of Agriculture, Khon Kaen University, Khon Kaen 40002, Thailand \\ ${ }^{3}$ Centre de coopération internationale en recherche agronomique pour de développement (Cirad), UMR innovation, 34398 Montpellier \\ cedex 5, France
}

\begin{abstract}
Climate vagaries and the lack of irrigation, frequently combined with coarse-textured sandy and unevenly distributed saline soils, explain low crop yields and the endemic relative poverty of the rural population in Northeast Thailand (NET). Local and regional trends in agriculturally-relevant rainfall variables were investigated using the Mann-Kendall test, modified to account for serial correlation, and applied to 17 stations across NET, and the regional average Kendall's statistic. Limited changes in rainfall frequency, intensity and seasonality are observed at individual stations over the study period (1953-2004). But we found a significant regional trend toward a wetter dry season. Based on an intimate knowledge of the local farming systems, we discuss the cropping systems adaptation to these rainfall changes. If the wetting of the dry season extends in the future, as expected according to most climate projections, households would not find it difficult to adapt, except for the problems caused by temperature rise, mainly due to their renowned adaptive capacity and high mobility that historically produced diverse and resilient rural livelihood systems.
\end{abstract}

Keywords: climate change adaptation / cropping systems / rainfall patterns / Thailand / trend

Résumé - Évolution de la pluviométrie au Nord-Est de la Thaïlande : les systèmes de culture pourront-ils s'adapter? Les irrégularités climatiques combinées à des conditions édaphiques défavorables expliquent les faibles rendements agricoles du Nord-Est de la Thaïlande, la région la plus pauvre du pays où l'agriculture est majoritairement non irriguée. Des tendances locales et régionales sont recherchées dans des variables pluviométriques contrôlant la production agricole. Une version modifiée du test de Mann-Kendall prenant en compte l'autocorrélation est appliquée aux chroniques de 17 stations dans cette région. La statistique régionale moyenne de Kendall est utilisée pour les tests régionaux. Quasiment aucune tendance locale n'est observée dans la fréquence, l'intensité et la saisonnalité des pluies sur la période d'étude (1953-2004). En revanche, la saison sèche est devenue significativement plus pluvieuse à l'échelle régionale. La capacité des systèmes de culture locaux à s'adapter à ce changement climatique est discutée. $\mathrm{Si}$, comme la plupart des modèles climatiques le prévoient, l'augmentation des pluies de saison sèche se confirme dans le futur, les agriculteurs n'éprouveront probablement pas de difficultés pour s'y adapter, à l'exception des problèmes liés à l'augmentation des températures. Leur capacité d'adaptation, forgée par des siècles de pratiques agricoles en régime pluvial incertain, et le recours aux migrations saisonnières ont permis l'établissement de systèmes agraires diversifiés et résilients.

Mots clés : adaptation aux changements climatiques / système de culture / régime de précipitation / Thaïlande / tendance

* Corresponding author: g. lacombe@cgiar.org 


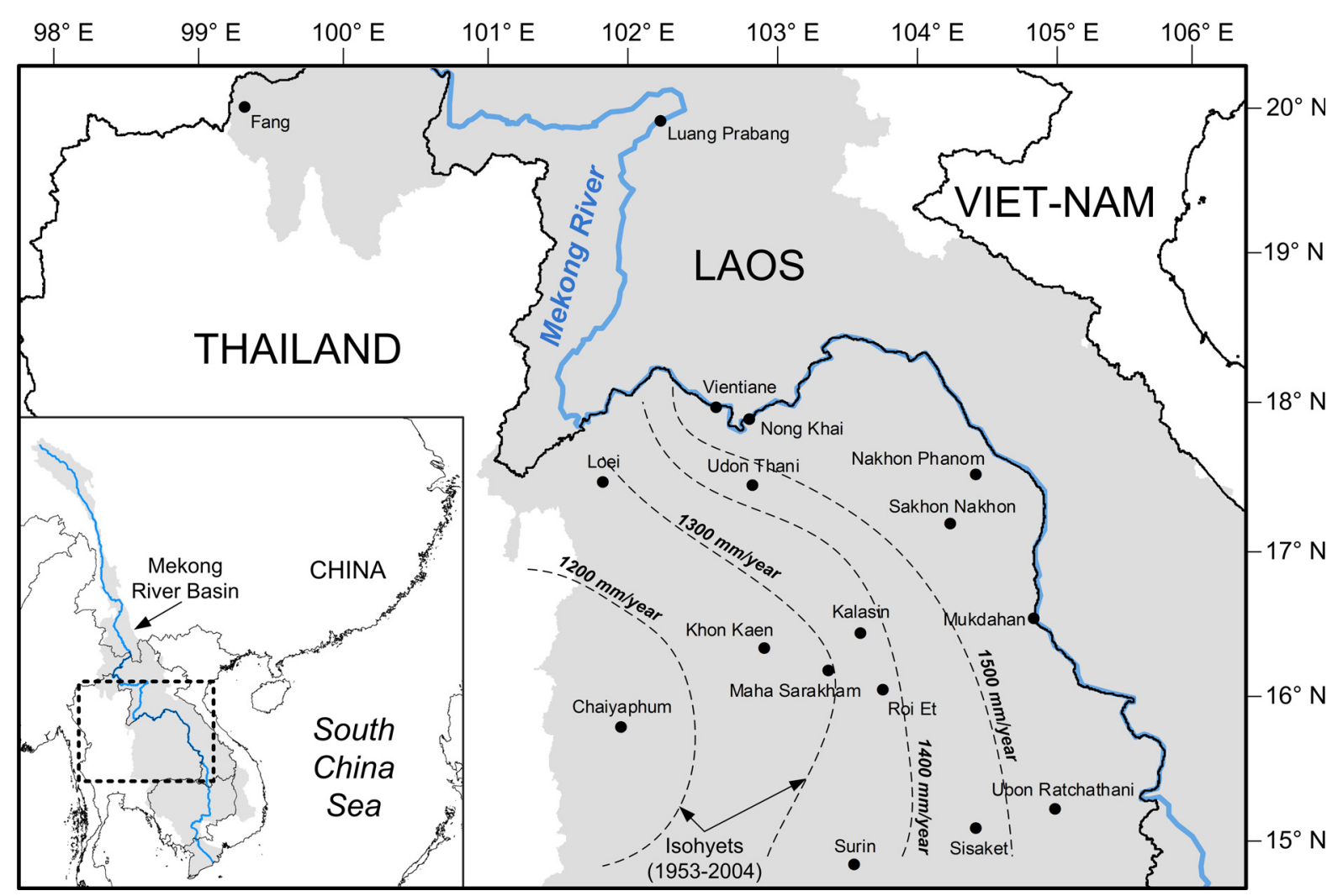

Fig. 1. Study area and location of the rainfall stations.

Fig. 1. Région d'étude et emplacement des stations pluviométriques.

\section{Introduction}

Globally, climate change is expected to have tremendous effects on agriculture through changes in temperature, rainfall patterns, and the frequency and intensity of extreme weather events (IPCC, 2014). While temperature projections exhibit consistencies between climate models, rainfall projections are still contradicting in many instances, despite significant improvements in climate sciences and computational capacity (Knutti and Sedlacek, 2013). Although the Mekong is one of the few large basins where climate models perform best in reproducing the monsoon, there is an overall uncertainty in projections of the Southeast Asian summer monsoon (Hasson et al., 2016). Against this background, insights into historical rainfall are necessary for both agricultural and water development planning. Detection of trends in rainfall time series is not straightforward, particularly in the Mekong where historic records are scarce, and rainfall generating mechanisms are complex (Hasson et al., 2013). The objectives of this study were thus to assess local and regional trends in agriculturally-relevant rainfall variables over the last half century in Northeast Thailand (NET), which is the Mekong sub-region where the longest rainfall records are available, and infer future challenges for cropping systems adaptation.

\section{Study area}

NET covers one third of the kingdom and is home to about 21 million inhabitants (Fig. 1). It is a sandstone plateau undulating between 100 and $500 \mathrm{~m}$ above sea level, characterized by erratic rainfall and poor coarse-textured sandy and unevenly distributed saline soils leading to low crop yields and endemic rural population poverty. About $80 \%$ of the population live in rural areas, mainly from agriculture and remittances received from millions of seasonal and permanent migrants.

\subsection{Climate}

Due to the Southeast Asian summer monsoon blowing humid air masses from the Indian Ocean, the rainy season concentrates about $80-90 \%$ of annual rainfall between May and October. The dry season caused by the East Asian winter monsoon brings dry and cold northeasterlies wind from November to April. The occurrence of the rainy season onset mainly relates to the surface temperature of the Pacific and Indian Oceans (Singhrattna et al., 2005). The multi-decadal variability of rainfall is partly due to the El Niño-Southern Oscillation (Räsänen and Kummu, 2013) and the North Pacific Oscillation (Wang et al., 2007).

\subsection{Cropping systems}

The staple food crop in NET is aromatic rainfed lowland rice (RLR) making $75 \%$ of the paddy area in the country, $95 \%$ of it being located in NET where only $7 \%$ of the farm land has access to irrigation (OAE, 2011). A single RLR cycle is performed annually with rice seedlings prepared in May and transplanted when there is sufficient amount of ponded water in the fields (Fig. 2). Typical problems possibly occurring during the same 


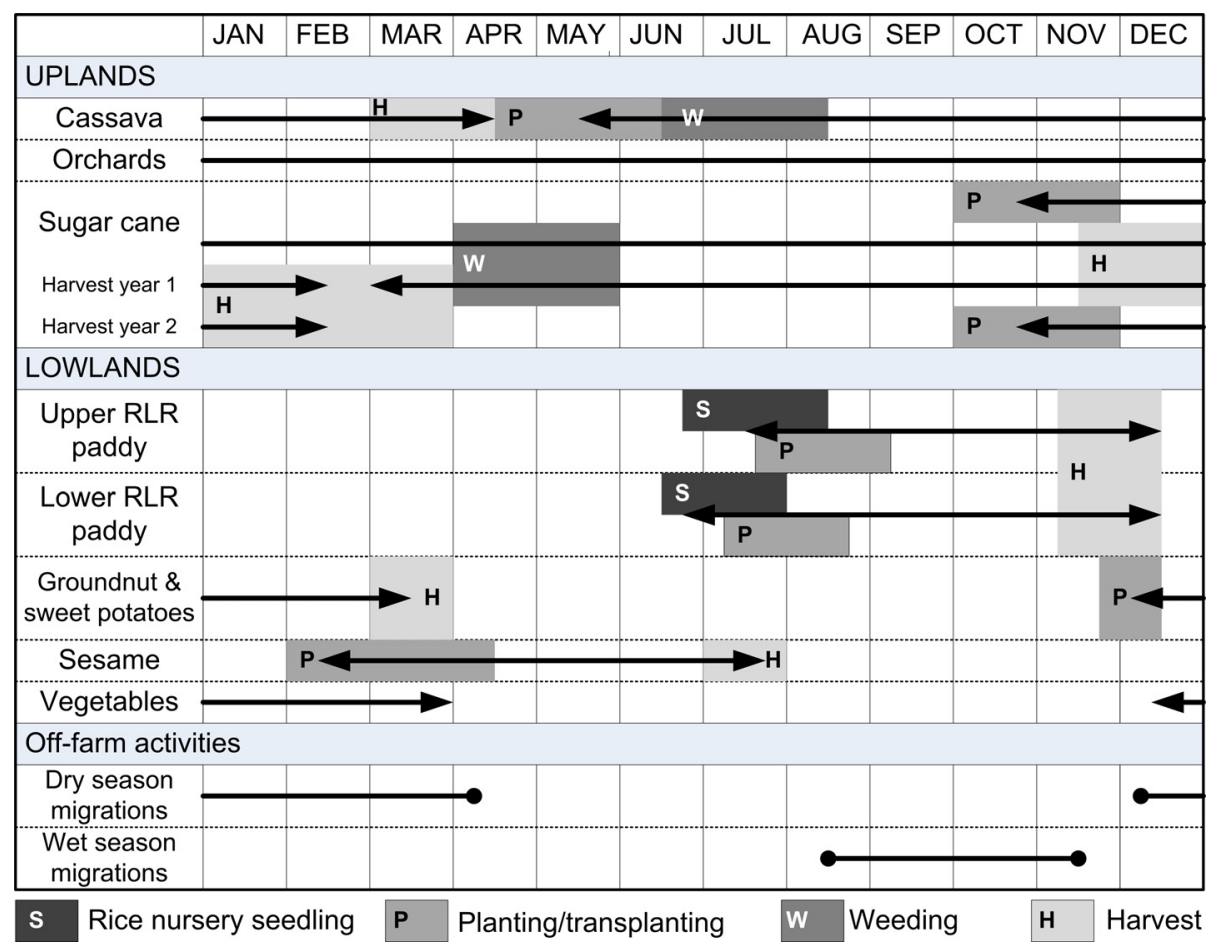

Fig. 2. Calendars of major crops in Northeast Thailand, adapted from Barnaud (2002) and Devillers and Cousinou (2003).

Fig. 2. Calendriers des principaux cycles culturaux dans le Nord-Est de la Thaïlande, adapté de Barnaud (2002), et Devillers et Cousinou (2003).

crop year include dry spells in the early rainy season and deep flooding at the peak of the wet monsoon in September. Farmers usually sow several rice seedling nurseries at different dates and elevations to minimize risks of total crop failure. If the rainy season is delayed or too weak, farmers do not transplant rice but practice direct-seeding, which produces lower yields mainly due to weed infestation (Sanusan et al., 2010). Double cropping systems are limited to groundnut and sweet potato after RLR, and sesame before RLR (Polthanee and Marten, 1986). While the initial stage of the cycle (December-January) relies on residual soil moisture, light rainfall during the second part (February-March) provides yields up to 2 and $6 \mathrm{t}^{-\mathrm{ha}^{-1}}$ for groundnuts and sweet potatoes, respectively (Polthanee, 1991). Sesame, planted between February and April, and harvested in late July, relies on a mix of residual moisture from the previous rainy season and pre-rainy season light rainfall (Fig. 2). These double-cropping systems tend to be abandoned because of unfavourable climatic constraints including erratic rainfall, especially during the earliest stages of the rainy season, and rising temperature depleting soil moisture through increased evapotranspiration (Polthanee and Marten, 1986; Polthanee and Promkhambut, 2014).

The main industrial crops are sugarcane and cassava. Sugarcane is usually located above the paddies where the soil productivity is too low for RLR. It is planted at the end of the rainy season when the soil moisture decreases but still allows ploughing with reduced efforts. The development then stops at the peak of the dry season. Harvest extends from December to March. Ratooning starts as soon as there is enough water after harvest (mostly in April) and can last two years allowing two additional harvests. Cassava is usually preferred to sugarcane in water deficient areas on sandy soils because of its higher drought-tolerance (Polthanee et al., 2014). A diverse range of mainly vegetable and horticultural crops are traditionally planted on the bank of rivers after water recedes at the end of the rainy season. This small-scale dry season production is for home-consumption and local markets (Fig. 2).

The conversion of forest to RLR began centuries ago in lowland areas. In 1950, forests covered more than half of NET (Sutthipibul, 1987). Thereafter, deforestation extended to upland areas where cash crops stimulated the emerging market economy. In $2009,36 \%$ of NET was covered by RLR, $16 \%$ by forest, $10 \%$ by annual crops, $4 \%$ by tree plantations, most of the remaining land being non-agricultural surface (MOA, 2010). Despite the lack of scientific evidence, the rapid deforestation that occurred over the last half century is often blamed as a major cause for the recurrent droughts that have been faced by farmers in the region.

\section{Material and methods}

\subsection{Rainfall variables}

Quality-controlled daily rainfall time series were provided by the Mekong River Commission for 17 stations in NET covering the period January 1953-December 2004 (Tab. 1). Thirty annual variables were derived from the daily data to capture the main climate features that control rainfed agricultural production. They are grouped into five categories.

\subsubsection{Timing of the rainy season (variables 1 to 3 )}

These variables correspond to the ordinal dates (number of days since January 1st) of the onset and retreat of the 
Table 1. Rainfall stations.

Tableau 1. Stations pluviométriques.



rainy season (variables 1 and 2, respectively), and of the first day of the rainiest 5-day period (variable 3), which coincides, with the rainfall peak of the rainy season. The onset of the rainy season was defined as the first day of the first 10-day period that meets two conditions: the 10-day rainfall depth is higher than the mean 10-day rainfall depth averaged over the period 1953-2004, and at least two of the next three 10-day periods satisfy the first condition. Because of the high rainfall variability, the variations between consecutive 10-day rainfall depths were first smoothed by a 3 -time-step moving average. The retreat of the rainy season was defined by symmetrical conditions, starting from the end of the calendar year and moving backward through the 10-day periods. Figure 3 in Lacombe et al. (2012) illustrates how variables 1 and 2 are defined. Farming practices and crop yields are closely related to the occurrence of the rainy season, particularly its onset. A delayed rainy season onset may result in delayed transplanting of RLR seedlings or poor emergence and early vegetative growth of crops. A delayed retreat of the rainy season may result in excess soil moisture before and during rice harvest with risks of yield and grain quality losses.

\subsubsection{Extreme events (variables 4 and 5)}

Variable 4 is the total rainfall depth of the rainiest 5-day period. Variable 5 corresponds to the greatest number of consecutive rainy season days with less than $1 \mathrm{~mm}$ of rainfall per day. It reflects farmers' drought definition, which associates drought to extended dry spells during the wet season (Amir Faisal et al., 2014). These extreme events create anoxic conditions through prolonged flood submersion, or drought stress, reducing crop yields.

\subsubsection{Intensity index (variable 6)}

The intensity index is the number of rainiest days that cumulate $67 \%$ of annual rainfall depth (Sun et al., 2006). A low index is associated to a rainfall pattern with few but heavy rainy days while a large index reflects a more regular distribution of rain events in the year.

\subsubsection{Seasonal rainfall depths (variables 7 to 18)}

These 12 variables correspond to the cumulative rainfall depth for different pairwise associations of three periods (whole year, rainy season and dry season) and four ranges of daily rainfall depths (whole range, low, medium and high rainfall). The low, medium and high ranges of daily rainfall were determined so that the cumulative daily rainfall depths within each of these three ranges are the same over the study period.

\subsubsection{Seasonal numbers of rainy days (variables 19 to 30 )}

These 12 variables correspond to the number of rainy days (rain $>1 \mathrm{~mm} /$ day) for the similar pairwise combinations of periods and daily rainfall ranges as those defined for variables 7-18.

\subsection{Local and regional trend tests}

Each of the 510 annual time series (30 variables at 17 stations) were tested for the presence of trends with the Mann-Kendall test (Mann, 1945; Kendall, 1975), one of the most frequently used trend detection tests applied to hydrometeorological time series. This non-parametric test is robust as it does not require the data to follow any particular statistical 

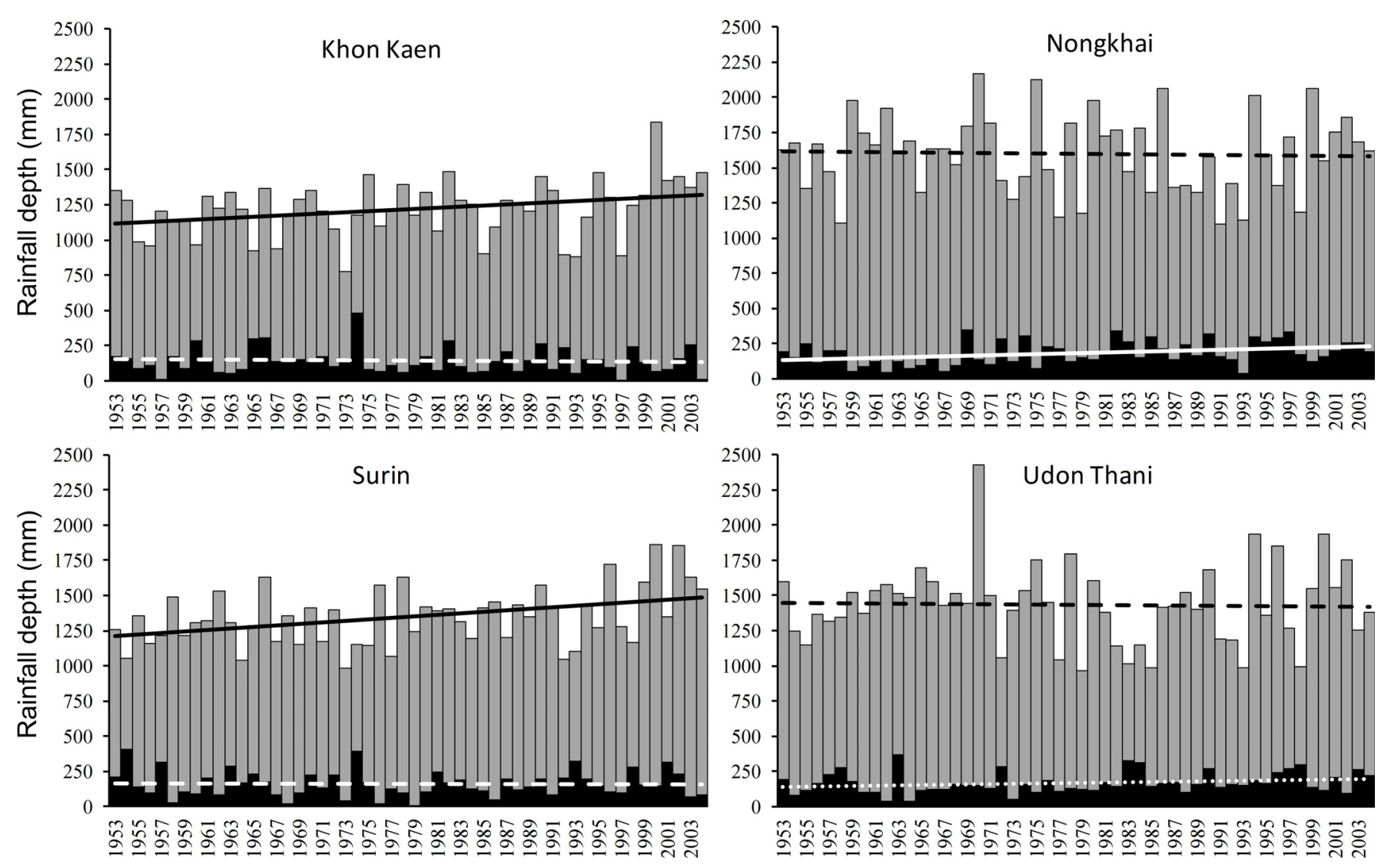

Fig. 3. Time series for annual (grey) and dry season rainfall (black). Solid trend line is significant at $95 \%$ confidence level. Dotted trend line is significant at $90 \%$ confidence level. Dashed trend line is statistically insignificant.

Fig. 3. Chroniques des pluies annuelles (gris) et de saison sèche (noir). Ligne continue : tendance significative au seuil de $95 \%$. Ligne pointillée : tendance significative au seuil de $90 \%$. Ligne en tirets : tendance non significative.

distribution and it has low sensitivity to outliers. A modified version of this test (Hamed, 2008) was used to account for possible auto-correlations and to minimize the related overestimation of trend significance. Trend slopes were calculated with the Sen's slope estimator (Sen, 1968).

This modified Mann-Kendall test determines whether a trend exists locally but does not confirm if a trend is evident throughout an entire region. The field significance (Vogel and Kroll, 1989), equivalent to the statistical significance of a regional trend, indicates whether a trend emerges from a group of stations in the same region. It was calculated as follows. Possible auto-correlation was first removed by pre-whitening the rainfall time series, i.e. by assuming a first-order autocorrelation structure and removing it from the time series (Hamed, 2009). A regional average Kendall's statistic (Douglas et al., 2000) was calculated for each one of the 30 rainfall variables using a re-sampling technique (Kundzewicz and Robson, 2004). The field significance associated with the regional Kendall's statistic was finally derived from the re-sampled time series using the Weibull plotting position formula. Two confidence levels of trend significance $(90 \%$ and 95\%) were considered at both local and regional scales.

It should be noted that different auto-correlation structures are considered in this analysis: long-term persistence at local level and first-order auto-correlation at regional level.
Assuming a first-order auto-correlation at both local and regional levels would enable an accurate comparison of local and regional significances of trends, as performed in Lacombe et al. (2012). However, this alternative approach, although more consistent, might be less accurate. Indeed, the long-term persistence, not easily accountable in the regional trend test, better reflects the natural behaviour of meteorological time series at the local level, hence our proposed approach.

\section{Results}

Out of the 510 tested time series, only 44 and 63 exhibit a trend significant at the $95 \%$ and $90 \%$ confidence levels, respectively (Tabs. 2, 3 and 4). Significant trends in the timing of the rainy season (variables 1-3), in the intensity of extreme events (variable 4), and in the intensity index (variable 6) are almost inexistent. Only four stations exhibit significant trends in the duration of dry spells (variable 5) (Tab. 2). Among the 24 significant trends in cumulative rainfall depths, 20 are positive. Among the 26 significant trends in the number of rainy days, 21 are positive. The few negative trends are observed during the rainy season only, indicating that rainy season trends are more heterogeneous in direction than those, uniformly positive, observed during the dry season (Tabs. 3 and 4). 
Table 2. Sen's slopes and significance of trends in variables 1-6.

Tableau 2. Pentes et significativités des tendances pour les variables 1-6.

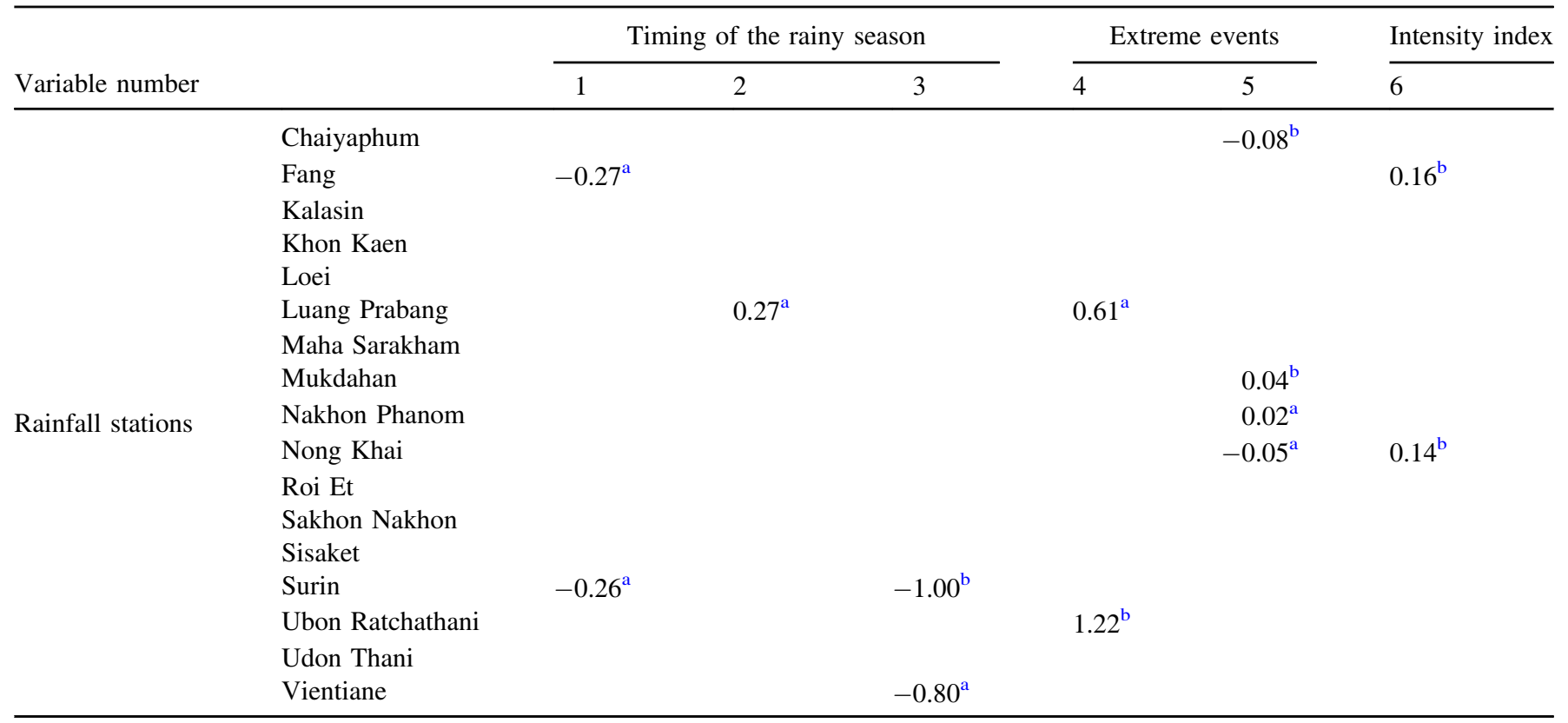

Field significance

${ }^{a} 90 \%$ significance.

${ }^{\mathrm{b}} 95 \%$ significance.

Table 3. Sen's slopes and significance of trends in variables 7-18.

Tableau 3. Pentes et significativités des tendances pour les variables 7-18.

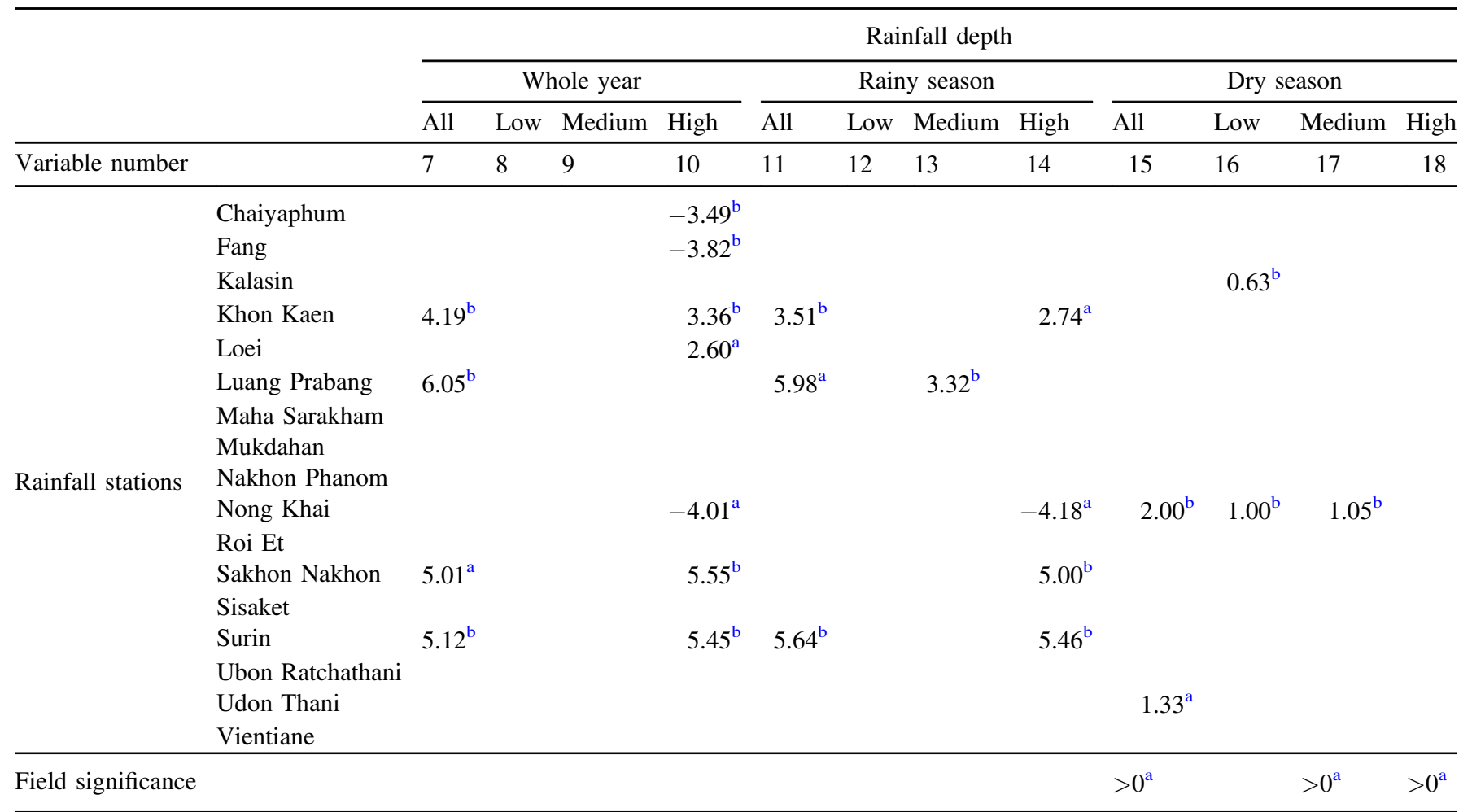

${ }^{\text {a }} 90 \%$ significance.

b $95 \%$ significance. 
Table 4. Sen's slopes and significance of trends in variables 19-30.

Tableau 4. Pentes et significativités des tendances pour les variables 19-30.

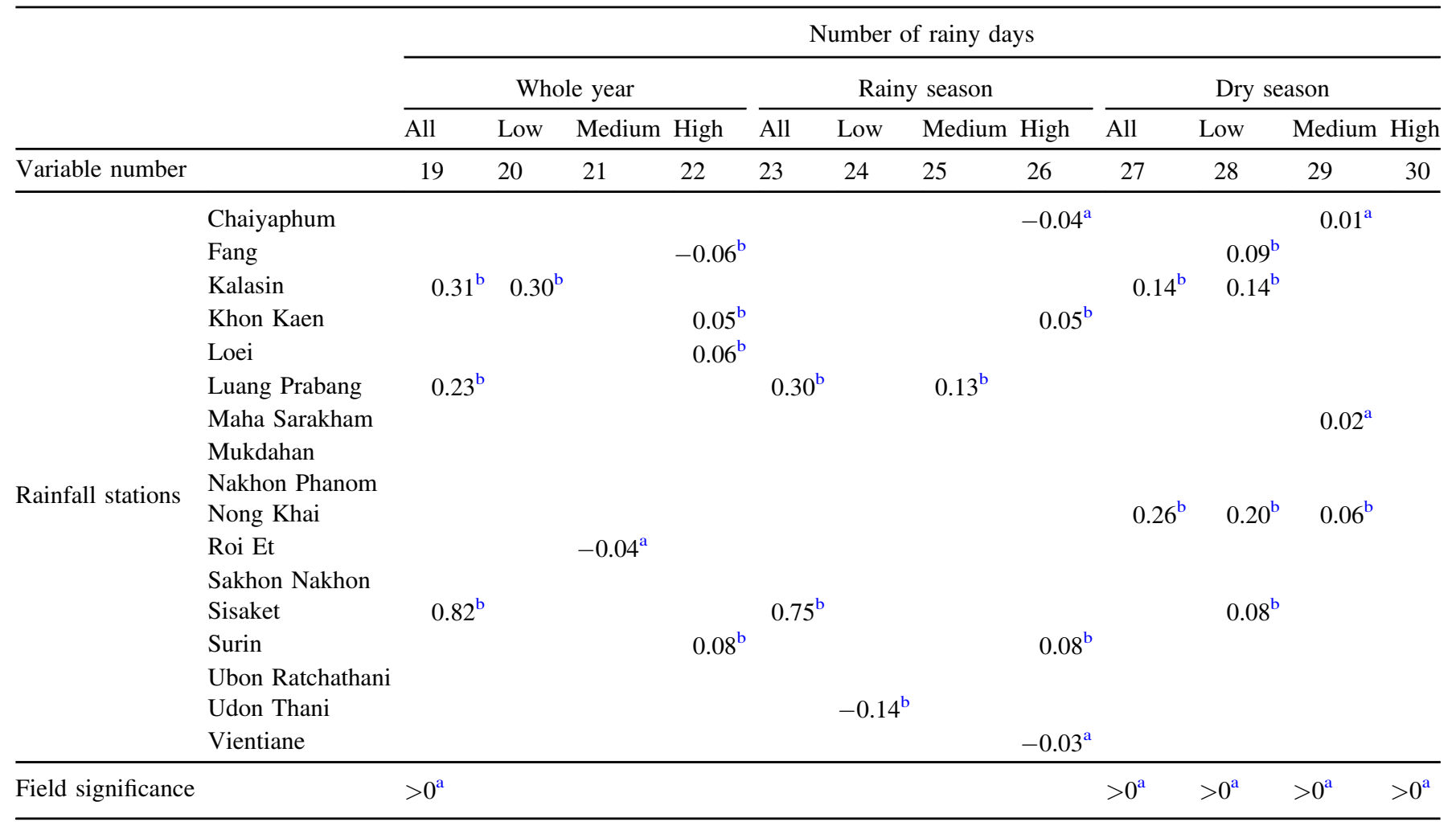

${ }^{\text {a }} 90 \%$ significance.

b $95 \%$ significance.

Figure 3 displays annual and dry season rainfall time series at four stations where contrasting trends are observed. In Nongkhai and Udon Thani, dry season rainfall has significantly increased while annual rainfall does not exhibit any significant trend. In contrast, in Surin and Khon Kaen, annual rainfall has significantly increased while dry season rainfall does not exhibit any significant trend. This comparison illustrates two types of heterogeneities:

- the complex behaviour of climate trends which can reveal contrasting trend significances across seasons, though at the same location;

- the high spatial variability of rainfall trends directions between stations distant by less than $200 \mathrm{~km}$.

Despite insignificant trends at most stations in the onset and retreat of the rainy season (Tab. 2), Figure 4 shows that high inter-annual variability exists. The variability of the onset (standard deviation $=17$ and 22 days in Nakhon Phanom and Surin, respectively) is greater than that of the retreat (standard deviation $=11$ and 13 days, respectively). This difference illustrates the difficulty for farmers to determine the appropriate sowing time while harvesting time is mainly determined by the photoperiodicity of their RLR cultivars.

Figure 5 shows that the few $90 \%$-field significant regional trends correspond to increases in rainfall depths and numbers of rainy days during the dry season mainly (Tabs. 3 and 4). Except for the timing of the rainy season onset and of the 5-day rainiest period (variables 1 and 3 ) exhibiting insignificant declining regional trends, all other variables exhibit rising regional trends, revealing an overall increase of rainfall depths and number of rainy days during both seasons. This highlights the importance of evaluating regional trends, which not only indicate the spatial extent of a changing pattern but also enable the detection of long-term changes that remain insignificant at individual stations due to the high variability of small-scale rainfall events and related sampling issues.

\section{Discussion}

The ability of the Mann-Kendall test to detect true trend in climate time series might be reduced when the tested variable is discrete and includes several ties as in the case of variable 5 (duration of longest dry spells). We plotted the statistical significance of the local trends in this variable against their slope and found that the lower detection threshold (90\%) corresponds to a slope equivalent to an additional 1.6 day of mean longest dry spell over the 52-year study period. This result confirms the ability of the test to detect slight changes in the studied rainfall variables.

Increased dry season rainfall in NET was found to be consistent with wider on-going climate dynamics observed in East Asia and explained by the weakening of the East Asian winter monsoon (Zhou, 2011). These changes were attributed to global warming (Zhang et al., 2011), indicating that rainfall is likely to continue increasing in the future. This wetting tendency may appear counterintuitive. 2015 has been the driest 

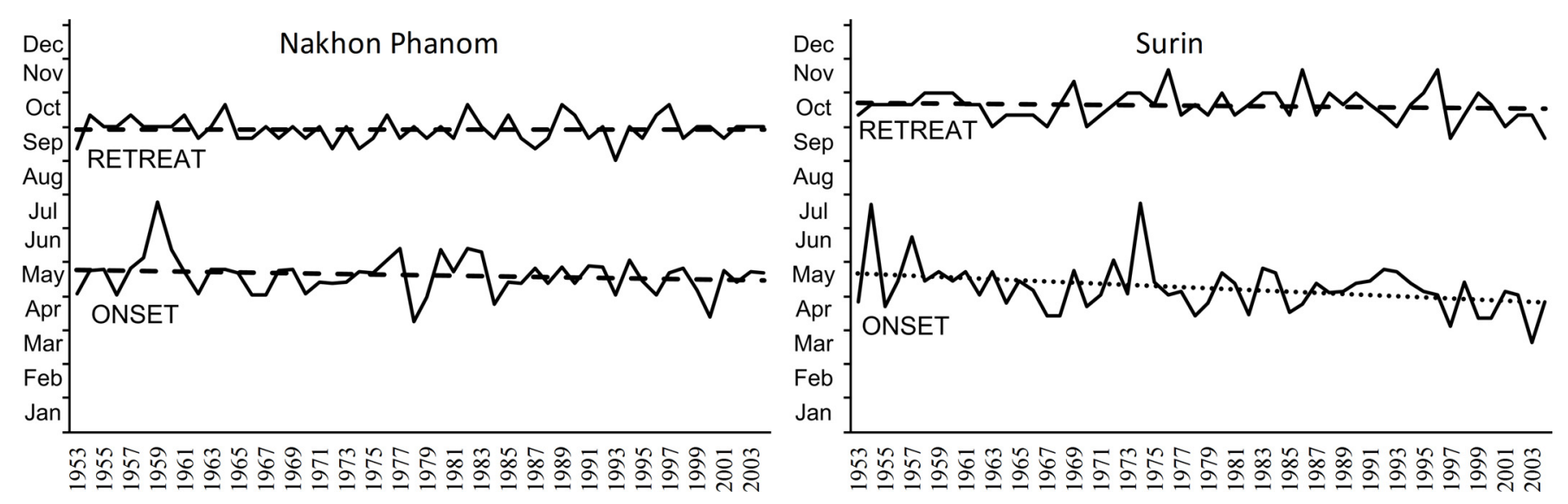

Fig. 4. Occurrence of the onset and retreat of the rainy season. Dotted trend line is significant at $90 \%$ confidence level. Dashed trend lines are statistically insignificant.

Fig. 4. Évolution de la date de début et de fin de la saison des pluies. Ligne pointillée : tendance significative au seuil de $90 \%$. Ligne en tirets : tendance non significative.

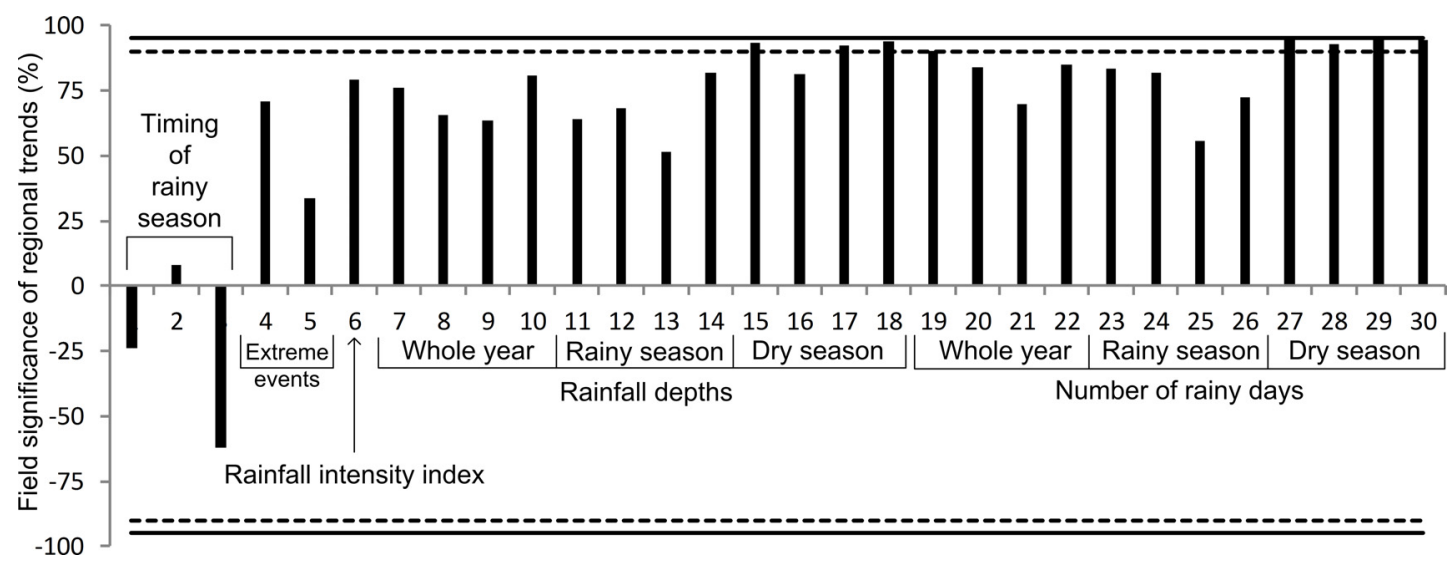

Fig. 5. Field significances of regional trends. Positive and negative values correspond to positive and negative trends, respectively. Solid horizontal line: $95 \%$ significance level. Dotted horizontal line: $90 \%$ significance level. NB: field significance $=$ statistical significance of regional trend.

Fig. 5. Significativité des tendances régionales. Les valeurs positives et négatives correspondent aux tendances positives et négatives, respectivement. Les lignes horizontales continues et pointillées correspondent aux seuils de significativité de $95 \%$ et $90 \%$, respectivement.

year since 1995 in Southeast Asia, due to an extreme El Niño event (FAO, 2015). Such episodes remain in the memories while insignificant and gradual increases in rainfall go unnoticed, thus possibly giving the impression that rainfall has reduced over recent decades (Amir Faisal et al., 2014).

Mean dry season rainfall increased by $12 \mathrm{~mm}$ from 1953 to 2004. Although it is statistically significant at the regional level, this slight increase corresponds to about $7 \%$ of the mean total dry season rainfall, far lower than the typical crop water requirements in NET which vary from $500 \mathrm{~mm}$ to $1,500 \mathrm{~mm}$ per cropping cycle (Allen et al., 1998).

No effect of increased dry season rainfall is expected on RLR since rice quality is mainly controlled by the number of rainy days during the rainy season (Polthanee and Promkhambut, 2014), which did not vary significantly (Tab. 4). Due to the absence of regional trends in the rainy season retreat, the increase in dry season rainfall is unlikely to occur in its earliest phase, leading to no change in the risk of damaged quality of the paddy at harvest. Similarly, the absence of regional trend in the rainy season onset is unlikely to accelerate the switch from RLR transplanting to direct seeding. Increased rainfall in the early dry season is unfavourable for groundnut plantation because it creates a hard soil surface and soil crusting leading to poor germination, more weeds, and often the need to plough again and replant the crop. But additional rainfall in FebruaryMarch is favourable after pegging and during pod filling stage. Additional rainfall at the end of the dry season could contribute to secure the establishment of sesame before RLR but this system remains risky due to the highly variable rainy season onset (Fig. 4).

The deep rooting system and fast crop establishment of sugarcane will be favoured by additional rain at the beginning 
of the dry season. The limited additional dry season rainfall combined with coarse textured soils in these uplands should not hamper the harvest and the transport of the cane by trucks. No significant impact of additional rainfall in the dry season on cassava is expected as most of the crop growth occurs during the wet season (Fig. 2). Recently, rubber plantations have been established in the more humid areas of the region and a wetter dry season will benefit this relatively new perennial crop.

Vegetables and horticultural crops planted on the bank of rivers will benefit from a wetter dry season, especially during its cooler first half. A moderate increase in dry season rainfall may sustain river base-flow at a higher level than currently observed, thus benefiting gardens grown on river banks. But at this stage, the detected increase in rainfall seems too limited to help recharge the shallow aquifers and small ponds on which these systems depend frequently to expand their planted areas.

\section{Conclusions}

While positive effects of the detected change in rainfall pattern on the existing cropping systems dominate, it is still far too limited to stimulate farmers' switch to new types of mono or double cropping systems, or to use more external inputs, in order to increase crop yields. Benefit from additional dry season rainfall remains marginal but more remarkable effects are expected in the future if these trends persist, as expected according to the most updated climate projections for the East Asian winter monsoon ( $\mathrm{Xu}$ et al., 2016). The benefit of additional rainwater for crop production should also be considered in light of the expected warming trend. Above $35{ }^{\circ} \mathrm{C}$, a temperature threshold that tends to be exceeded more frequently at rice flowering time in NET (Pornamnuaylap et al., 2014), pollen fertility decreases, inducing yield declines. Several naturally spontaneous adaptations include early anthesis time, panicle cooling through transpiration, and the selection of heat-tolerant varieties (Lafarge et al., 2016). Increased temperature also depletes soil water reserves through enhanced evapotranspiration. The benefit from additional rainfall is enhanced if drought risks are moderated by supplemental irrigation water resources, such as the expansion of thousands of small and multipurpose on-farm ponds installed across NET during the past two decades. They allow the practice of integrated farming systems combining rice, fish rearing, fruit and vegetable production and contribute to food security at the household level across this region. For centuries, the very adaptive and resilient Lao-Isan population in NET has been facing climate uncertainties with up to sixmonth dry season with scorching temperatures in March-April forcing them to practice internal seasonal migrations to wet spots and to secure part of their food from non-timber forest products. More recently migrations head to urban centres and foreign countries to generate off-farm incomes supporting the continuation of small-scale family farming. Gaining from this traditional flexibility, there is no doubt that NET farmers will find ways to adapt to the limited change in rainfall distribution reported here.

Acknowledgements. This study was funded by the CGIAR Research Program on Climate Change, Agriculture and Food
Security (CCAFS). The authors are grateful to the Mekong River Commission for the provision of rainfall data.

\section{References}

Allen RG, Pereira LS, Raes D, Smith M. 1998. Crop evapotranspiration - guidelines for computing crop water requirements. In: Irrigation and drainage paper 56. Rome (Italy): FAO, 326 p.

Amir Faisal AH, Polthanee A, Promkhambut A. 2014. Farmers' perception of drought and its impact on a community livelihood in rural Northeastern Thailand. Khon Kaen Agric J 42(3): 427-442.

Barnaud C. 2002. Analyse diagnostic de la situation agraire du village de Ban Hin Lad, Nord-Est de la Thaïlande. INAP-G, 41 p.

Devillers E, Cousinou L. 2003. Analyse-diagnostic comparative des systèmes agraires de Kut Chieng Mee et Nong Saeng, deux villages dans La Province de Khon Kaen, Nord-Est de la Thaïlande. INAP-G, 89 p.

Douglas EM, Vogel RM, Kroll CN. 2000. Trends in floods and low flows in the United States: impact of spatial correlation. J Hydrol 240: 90-105.

FAO. 2015. El Niño in Asia. Prolonged dry weather in several countries affecting plantings and yield potential of the 2015 main season food crops. GIEWS update. Rome (Italy): FAO, $10 \mathrm{p}$.

Hamed KH. 2008. Trend detection in hydrologic data: the MannKendall trend test under the scaling hypothesis. J Hydrol 349: 350-363.

Hamed KH. 2009. Enhancing the effectiveness of prewhitening in trend analysis of hydrologic data. J Hydrol 368: 143-155.

Hasson S, Lucarini V, Pascale S. 2013. Hydrological cycle over South and Southeast Asian river basins as simulated by PCMDI/CMIP3 experiments. Earth Syst Dyn 4: 199-217.

Hasson S, Pascale S, Lucarini V, Böhner J. 2016. Seasonal cycle of precipitation over major river basins in South and Southeast Asia: a review of the CMIP5 climate models data for present climate and future climate projections. Atmos Res 180: 42-63.

IPCC. 2014. Climate change 2014: synthesis report. In: Contribution of working groups I, II and III to the Fifth Assessment Report of the Intergovernmental Panel on Climate Change. Geneva (Switzerland): IPCC, $151 \mathrm{p}$.

Kendall MG. 1975. Rank correlation methods. London (England): Griffin.

Knutti R, Sedlacek J. 2013. Robustness and uncertainties in the new CMIP5 climate model projections. Nature Climate Change 3: 369-373. doi: 10.1038/NCLIMATE1716.

Kundzewicz ZW, Robson AJ. 2004. Change detection in hydrological records-a review of the methodology. Hydrol Sci J 49(1): 7-19.

Lacombe G, McCartney M, Forkuor G. 2012. Drying climate in Ghana over the period 1960-2005: evidence from the resamplingbased Mann-Kendall test at local and regional levels. Hydrolog Sci J 57(8): 1594-1609.

Lafarge T, Julia C, Baldé A, Ahmadi N, Muller B, Dingkuhn M. 2016. Rice adaptation strategies in response to heat stress at flowering. In: Torquebiau E, ed. Climate change and agriculture worldwide. Netherlands: Springer/Cirad, p. 31-43.

Mann HB. 1945. Nonparametric tests against trend. Econometrica 13: 245-259.

MOA. 2010. Agriculture statistics. Bangkok: Ministry of Agriculture (MOA). Available at http://www.web.nso.go.th/ [2016/05/09].

OAE. 2011. Agricultural statistics of Thailand 2011. Office of Agricultural Economics (OAE). Available at http://www.oae.go.th/ [2016/07/09].

Polthanee A. 1991. Cultivation of peanuts after rice in rainfed areas of Northeast Thailand: farmers' approach. AGRIS 7(1): 70-76. 
Polthanee A, Marten G. 1986. Rainfed cropping systems in Northeast Thailand. In: Maten G, ed. Traditional agriculture in Southeast Asia.Boulder and London (United Kingdom): Westview Press, p. 103-131.

Polthanee A, Promkhambut A. 2014. Impact of climate change on rice-based cropping systems and farmers' adaptation strategies in Northeast Thailand. Asian J Crop Sci 6(3)262-272. doi: 10.3923/ajcs.2014.

Polthanee A, Janthajam C, Promkhambut A. 2014. Growth, yield and starch content of cassava following rainfed lowland rice in Northeast Thailand. Int J Agric Res 9(6): 319-324.

Pornamnuaylap D, Limsakul A, Limtong P, Chidthaisong A. 2014. Evaluating the potential impacts of high temperature on rice production in Northeast Thailand. J Sustain Energ Environ 5, 65-74.

Räsänen TA, Kummu M. 2013. Spatiotemporal influences of ENSO on precipitation and flood pulse in the Mekong River Basin. J Hydrol 476: 154-168.

Sanusan S, Polthanee A, Audebert A, Seripong S, Mouret JC. 2010. Suppressing weeds in direct-seeded lowland rainfed rice: effect of cutting dates and timing of fertilizer application. Crop Prot 29: 927-935.

Sen PK. 1968. Estimates of the regression coefficient based on Kendall's tau. J Am Stat Assoc 63: 1379-1389.
Singhrattna N, Rajagopalan B, Kumar KK, Clark M. 2005. Interannual and interdecadal variability of Thailand summer monsoon season. J Climate 18: 1697-1708.

Sun Y, Solomon S, Dai A, Portmann RW. 2006. How often does it rain? J Climate 19: 916-934.

Sutthipibul V. 1987. Effects of diminishing forest area on rainfall amount and distribution in Northeast Thailand. Master Thesis, Kasetsart University (Bangkok), 133 p.

Vogel RM, Kroll CN. 1989. Low-flow frequency analysis using probability plot correlation coefficients. J Water Res Pl-ASCE 115 (3): 338-357.

Wang L, Chen W, Huang R. 2007. Changes in the variability of North Pacific Oscillation around 1975/1976 and its relationship with East Asian winter climate. J Geophys Res 112: D11110.

$\mathrm{Xu} \mathrm{M,} \mathrm{Xu} \mathrm{H,} \mathrm{Ma} \mathrm{J.} \mathrm{2016.} \mathrm{Responses} \mathrm{of} \mathrm{the} \mathrm{East} \mathrm{Asian} \mathrm{winter}$ monsoon to global warming in CMIP5 models. Int J Climatol 36: 2139-2155.

Zhang Q, Singh VP, Sun P, Chen X, Zhang Z, Li J. 2011. Precipitation and streamflow changes in China: changing patterns, causes and implications. J Hydrol 410: 204-216.

Zhou LT. 2011. Impact of East Asian winter monsoon on rainfall over Southeastern China and its dynamical process. Int J Climatol 31(5): 677-686.

Cite this article as: Lacombe G, Polthanee A, Trébuil G. 2017. Long-term change in rainfall distribution in Northeast Thailand: will cropping systems be able to adapt? Cah. Agric. 26: 25001. 